\title{
Utilisation of Recycled Aggregate as Coarse Aggregate in Concrete
}

\author{
Yong, P.C. ${ }^{1}$ and Teo, D.C.L. ${ }^{2}$
}

\begin{abstract}
In this rapid industrialised world, recycling construction material plays an important role to preserve the natural resources. In this research, recycled concrete aggregates (RCA) from site-tested concrete specimens were used. These consist of 28-days concrete cubes after compression test obtained from a local construction site. These concrete cubes are crushed to suitable size and reused as recycled coarse aggregate. The amount of recycled concrete aggregate used in this research is approximately $200 \mathrm{~kg}$. Many researchers state that recycled aggregates are only suitable for non-structural concrete application. This research, however, shows that the recycled aggregates that are obtained from site-tested concrete specimen make good quality concrete. The compressive strength of recycled aggregate concrete (RAC) is found to be higher than the compressive strength of normal concrete. Recycled aggregate concrete is in close proximity to normal concrete in terms of split tensile strength, flexural strength and wet density. The slump of recycled aggregate concrete is low and that can be improved by using saturated surface dry (SSD) coarse aggregate.
\end{abstract}

Keywords: Recycled Concrete Aggregate (RCA), Recycled Aggregate Concrete (RAC), Recycled Concrete, Recycled Aggregate

\section{INTRODUCTION}

$\mathrm{R}$ apid industrial development causes serious problems all over the world such as depletion of natural aggregates and creates enormous amount of waste material from construction and demolition activities. One of the ways to reduce this problem, is to utilise recycled concrete aggregate (RCA) in the production of concrete [1].

Many significant researches have been carried out to prove that recycled concrete aggregate could be a reliable alternative as aggregate in production of concrete. As widely reported, recycled aggregates are suitable for non-structural concrete applications [2]. Recycled aggregates also can be applied in producing normal structural concrete with the addition of fly ash and condensed silica fume etc [3].

Strength of concrete is affected by the type of coarse aggregated used. It is necessary to know the characteristics of RCA and the effects of using RCA in concrete. There are limited reliable data on the use of RCA in concrete and thus, more researches on the utilisation of RCA should be carried out. In this research, the main concern is the testing of RCA and the resulting concrete made by it.

RCA is the main component of old concrete and for many reasons there is a need to re-use them [4]. Such recycling operations have the added benefit of reducing landfill disposal, while conserving primary resources and reducing transport costs [2]. There are large amount of concrete wastages during construction and demolition stages in Sarawak. RCA can be obtained from these wastages for the production of new concrete.

For this study, only concrete cubes after testing at site are used to obtain RCA. The construction industry in Sarawak normally requires 6 cubes for testing from a mixture truck. Many local concrete producers use 150 x 150 cubes for compressive strength test. To pour $1000 \mathrm{~m}^{3}$ concrete, an average of $2 \mathrm{~m}^{3}$ to $4 \mathrm{~m}^{3}$ from it will be used for concrete cube tests. These tested cubes can be crushed and screened through portable, mobile or stationary recycle plants instead of being discarded after testing and increase disposal in landfill.

1 Student, Department of Civil Engineering, Faculty of Engineering, Universiti Malaysia Sarawak ,Sarawak, Malaysia, amberinayong@hotmail.com 2 Lecturer, Department of Civil Engineering, Faculty of Engineering, , Universiti Malaysia Sarawak, Sarawak, Malaysia , tdelsye@feng.unimas.my 
The use of RCA for the production of concrete involves breaking, removing, and crushing existing concrete into a material with specified size and quality. Recycling of concrete is important because it helps to promote sustainable development in the protection of natural resources, and reduces the disposal of demolition waste from old concrete. Unprocessed RCA is useful to be applied as many types of general bulk fill, bank protection, sub-basement, road construction, noise barriers and embankments. Processed RCA can be applied to new concrete for pavements, shoulders, median barriers, sidewalks, curbs and gutters, and bridge foundations. It also can be applied to structural grade concrete, soil-cement pavement bases, lean concrete and bituminous concrete [5].

Recycled aggregate normally has higher water absorption and lower specific gravity [6]. The density of recycled aggregate used is lower than the density of normal aggregate. Porosity of recycled aggregates is also much higher than those of natural aggregates [7]. Generally, the grading curves for recycled aggregate are continuous and they have similar fineness modulus for equivalent fraction [7].

Recycled aggregate concrete (RAC) is concrete made from recycled aggregate. It was found that the workability of fresh RAC decreases with an increase in recycled aggregate due to water absorption of mortar adhered to recycled aggregate [6].The strength of RAC is reported to be less by about $10 \%$ compared to normal concrete [8,9]. According to Tavakoli and Soroushian [10], concretes with recycled aggregate produced splitting tensile strengths higher than those obtained using natural aggregate. It was found that RAC with $100 \%$ replacement of recycled aggregate will have a decrease of $13 \%$ in flexural strength compared to normal concrete [3].

Poon and Chan [11] have studied the use of RAC in a project at Hong Kong Wetland Park. The highest concrete grade used was $35 \mathrm{MPa}$, while the slump of concrete was in the range of $75 \mathrm{~mm}$ to $100 \mathrm{~mm}$. The RAC was applied in pile caps, ground slabs, external works, mass concrete, minor concrete works and concrete blinding. The higher grade RAC is made by $20 \%$ replacement of recycled coarse aggregate (RCA); 100\% recycled aggregate replacement is used to produce lower grade concretes. A total amount of $12918 \mathrm{~m}^{3}$ of recycled aggregate concrete was used in this project [11].

\section{EXPERIMENTAL PROGRAM}

The main aim of this research project is to utilise recycled concrete as coarse aggregate for the production of concrete. It is essential to know whether the replacement of RCA in concrete is inappropriate or acceptable. Three types of aggregates are used in this project which include natural coarse aggregate, natural fine aggregate and RCA. Natural coarse aggregate used is microtonalite with maximum size of $25 \mathrm{~mm}$. Natural fine aggregate used is river sand and RCA used is crushed concrete from tested concrete cubes. Tests are carried out on these aggregates to determine the specific gravity and absorption; bulk density; moisture content and sieve analysis. After testing, a mix design is produced in accordance with the properties obtained from test results. Concrete is then produced with replacement of $0 \%, 50 \%$ and $100 \%$ of RCA as well as $100 \%$ replacement of saturated surface dry (SSD) RCA with the same mix proportion. Tests conducted on these concretes include the slump of fresh concrete. For the hardened concrete, the 28-days air-dry density, compressive strength, split tensile strength and flexural strength were determined. Except for the 28-days air-dry density, tests were conducted at the ages of 3, 7, 28 and 56 days and the results at each testing age are reported as an average. The engineering properties of the RAC were also compared to those of the reference concrete.

The natural fine aggregate used for producing concrete is river sand. The source of this sand is Batu Kitang River. The natural coarse aggregate available in the Civil Engineering Laboratory is microtonalite. The maximum size of this gravel is $25 \mathrm{~mm}$. Recycled aggregate used in this research is crushed concrete, i.e. RCA. The site tested concrete cubes of 28-days are crushed together using hammer. Since the natural aggregate is less than $25 \mathrm{~mm}$ in size, the recycled concrete is sieved through $25 \mathrm{~mm}$ sieve and $4.75 \mathrm{~mm}$ in a mechanical shaker. Recycled aggregate passing $25 \mathrm{~mm}$ and retained on $4.75 \mathrm{~mm}$ sieve is collected to produce recycled concrete.

The mix design is produced with the selected slump of $30 \sim 60 \mathrm{~mm}$, design compressive strength of $30 \mathrm{MPa}$ and the maximum aggregate size of $25 \mathrm{~mm}$. Other aggregate properties available from previous tests are used in the calculation for mix design. Numerous trial mixes are carried out to produce concrete with $0 \%$ replacement of RCA. This concrete serves as reference concrete (control concrete) and tests are conducted on this concrete to determine its properties. The other three mixes are carried out to produce concretes with 50\% and 100\% replacement of RCA as well as $100 \%$ replacement of SSD recycled concrete coarse aggregate. The concretes with replacement of RCA are tested and their properties determined. Directly after casting, the fresh concrete is covered with plastic sheet to avoid excess evaporation of water. The hardened concrete samples are then demoulded after 24 hours and submerged in a clean water bath for curing until the age of testing. 
The compression test is carried out according to BS1881-116 to determine the characteristic strength of the concrete. In this test, $100 \mathrm{~mm}$ standard cube mould is used for concrete mix. The apparatus should be clean and free from hardened concrete and superfluous water before testing [12].

The split cylinder test is performed according to ASTM C496 to find the tensile strength of a cylindrical concrete specimen. The cylindrical specimen is placed with its axis horizontally and subjected to a line load along the length of the specimen. The diameter and length of the cylindrical concrete are $100 \mathrm{~mm}$ and $204 \mathrm{~mm}$ respectively. Two wooden-bearing strips, $3.2 \mathrm{~mm}$ thick, $25 \mathrm{~mm}$ wide and slightly longer than the length of the specimen, are placed between the steel bars and the specimen to take account of deviations in the surface of the specimen [13].

The flexural strength test is carried out on a concrete beam with loading at the third points according to ASTM C78. In this test, a rigid steel form $51 \mathrm{~cm}$ long by $15 \mathrm{~cm}$ in the other two dimensions is needed. The loading machine should be able of applying the loads at a uniform rate without interruption [14].

\section{RESULTS AND DISCUSSION}

Table 1 shows the various properties of natural aggregate (gravel) and RCA obtained by testing. From the result, the bulk density of gravel is $1469.8 \mathrm{~kg} / \mathrm{m}^{3}$ and the RCA is $9.8 \%$ lower in bulk density than the gravel. The bulk specific gravity (dry), bulk specific gravity (wet) and apparent specific gravity of RCA are lower than those of gravel because of the lower density and higher water absorption in RCA. The absorption and moisture content of RCA are higher than those of gravel because of the cement paste which adhered to the recycled aggregate is high in porosity.

Table 1 Comparison of Properties on Gravel and Recycled Aggregate (RCA)

\begin{tabular}{|l|c|c|c|}
\hline Aggregate Properties & Gravel & $\begin{array}{c}\text { Recycled aggregate } \\
\text { (RCA) }\end{array}$ & Percent Difference (\%) \\
\hline Bulk specific gravity, Dry & 2.55 & 2.09 & 18.0 \\
\hline Bulk specific gravity, SSD & 2.56 & 2.14 & 16.4 \\
\hline Apparent specific gravity & 2.63 & 2.3 & 12.5 \\
\hline Absorption (\%) & 1.56 & 6.4 & 4.8 \\
\hline Bulk density (kg/m $\left.\mathbf{m}^{\mathbf{3}}\right)$ & 1469.8 & 1325.93 & 9.8 \\
\hline Moisture content (\%) & 1.9 & 4.46 & 2.6 \\
\hline
\end{tabular}

The mix design is first done according to the DoE (British) mix design method and numerous trial mixes were conducted to obtain the optimum mix. Once the optimum mix is determined, it is used to produce concrete with $50 \%$ and $100 \%$ replacement of RCA as well as 100\% replacement of SSD RCA. The constituents of this optimum mix proportion are shown in Table 2.

Table 2 Optimum Mix Proportion Used For Production of Concrete

\begin{tabular}{|c|c|c|c|c|}
\hline $\begin{array}{c}\text { Cement Quantity } \\
\left(\mathrm{kg} / \mathrm{m}^{3}\right)\end{array}$ & $\begin{array}{c}\text { Sand } \\
\left(\mathrm{kg} / \mathrm{m}^{3}\right)\end{array}$ & $\begin{array}{c}\text { Gravel } \\
\left(\mathrm{kg} / \mathrm{m}^{3}\right)\end{array}$ & $\begin{array}{c}\text { Mix Proportion By } \\
\text { Weight } \\
\text { (C: : : G) }\end{array}$ & $\begin{array}{c}\text { Water-Cement } \\
\text { Ratio (w/c) }\end{array}$ \\
\hline 457 & 521.10 & 967.80 & $1: 1.11: 2.07$ & 0.41 \\
\hline
\end{tabular}

The slump is taken for each mixing of concrete with $0 \%, 50 \%$ and $100 \%$ replacement of RCA. The results show that slump of concrete made with natural aggregates is higher while the concrete with $100 \%$ replacement of RCA has no slump. The low slump in RAC is caused by the high absorption of RCA (6.4\%) which absorbs water during the mixing process. It is recommended to use saturated surface dry (SSD) RCA to improve the workability of fresh concrete. From the results obtained, concrete made with 100\% SSD RCA has competitive slump compared to the concrete made with natural aggregate as shown in Table 3.

Table 3 Slump of Fresh Concrete for Different Mix

\begin{tabular}{|l|c|}
\hline \multicolumn{1}{|c|}{ Sample } & Slump (mm) \\
\hline Natural concrete (Control concrete) & 55 \\
\hline Recycled concrete (50\% replacement of RCA) & 10 \\
\hline Recycled concrete (100\% replacement of RCA) & 0 \\
\hline Recycled concrete (100\% replacement of SSD RCA) & 55 \\
\hline
\end{tabular}


Table 4 shows the results of the 28-days air-dry density of concrete. From the results, the air-dry density seems to increase slightly with the addition of RCA. This could be due to the higher absorption capacity of the recycled aggregate. When the water is absorbed by aggregate, more space left by the water being absorbed can be occupied by aggregates in a unit volume. Hence the density of recycled concrete is higher.

Table 4 28-days Air-Dry Density of Hardened Concrete

\begin{tabular}{|c|c|}
\hline Sample & Dry Density $\left(\mathrm{kg} / \mathrm{m}^{3}\right)$ \\
\hline Natural concrete (Control concrete) & 2265.2 \\
\hline Recycled concrete (50\% replacement of RCA) & 2316.8 \\
\hline Recycled concrete ( $100 \%$ replacement of RCA) & 2282.9 \\
\hline Recycled concrete (100\% replacement of SSD RCA) & 2257.9 \\
\hline
\end{tabular}

The natural aggregate and recycled aggregate are used to produce $100 \mathrm{~mm}$ concrete cubes for compression test. Figure 1 shows the results of compressive strength of concrete with $0 \%, 50 \%, 100 \%$ replacement RCA and 100\% replacement of SSD RCA. From the results, the compressive strength of concrete with 100\% replacement of RCA has the highest 3-day and 28day strength which reaches 40.24 MPa and 57.99 MPa respectively. The compressive strength of recycled concrete with $50 \%$ replacement of RCA is in close proximity with that of the control concrete. The compressive strength of recycled concrete with $100 \%$ replacement of SSD RCA is slightly higher than the control concrete but exhibits lower strength at 56 days. From the results obtained, it is observed that the development of compressive strength of recycled concrete is better during early stage but it exhibits lower compressive strength during later stage.

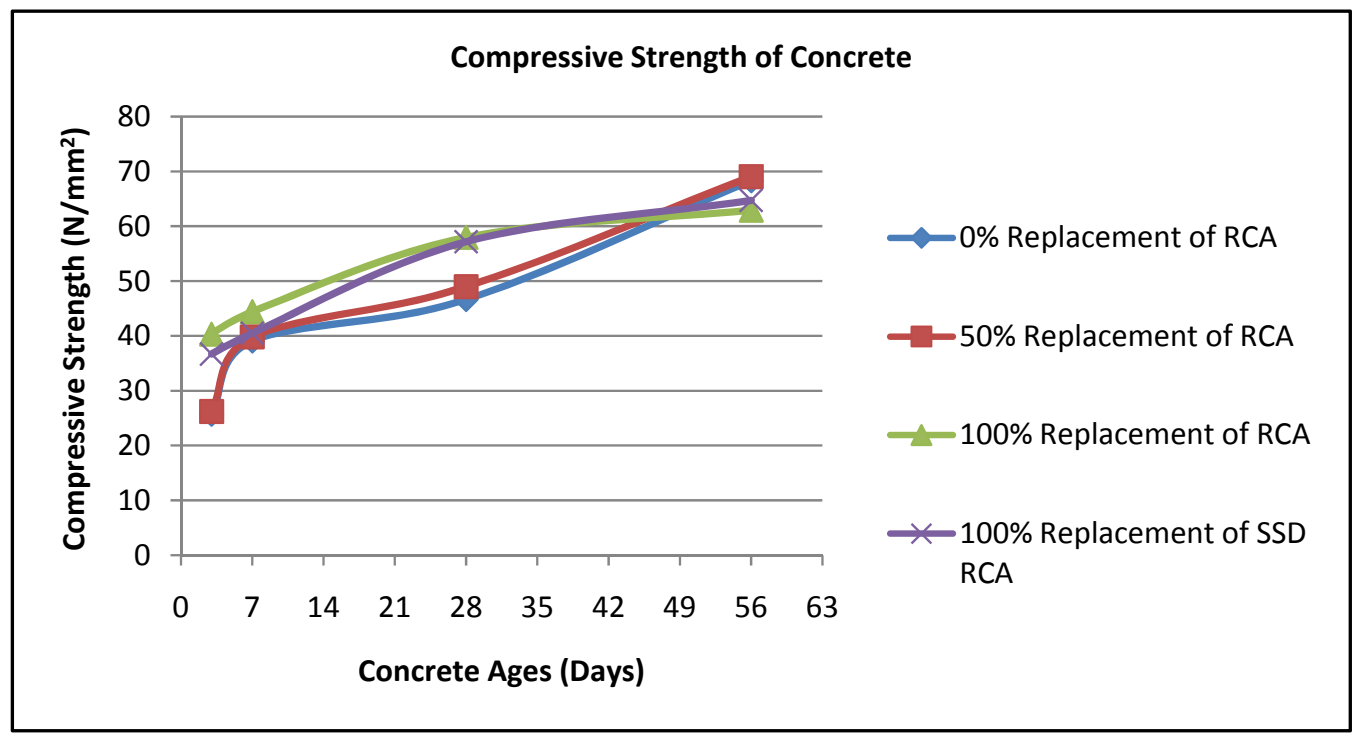

Figure 1 Compressive Strength of Hardened Concrete for Different Mix

Split cylinder test is carried out on each concrete sample to find split tensile strength of concrete cylinder. The results of the split tensile strength for the tested concrete samples are shown in Figure 2. The split tensile strength of recycled concrete with replacement of 50\% of RCA is approximately the same with the split tensile strength of the control concrete. The split tensile strength of recycled concrete with replacement of 100\% RCA and 100\% SSD RCA are both higher than split tensile strength of control concrete. The results show that concrete made with 100\% SSD RCA has the highest split tensile strength during early stage. As with the compressive strength, the split tensile strength of recycled concrete is higher during early stage but it gains strength at a slower rate during later stages. 


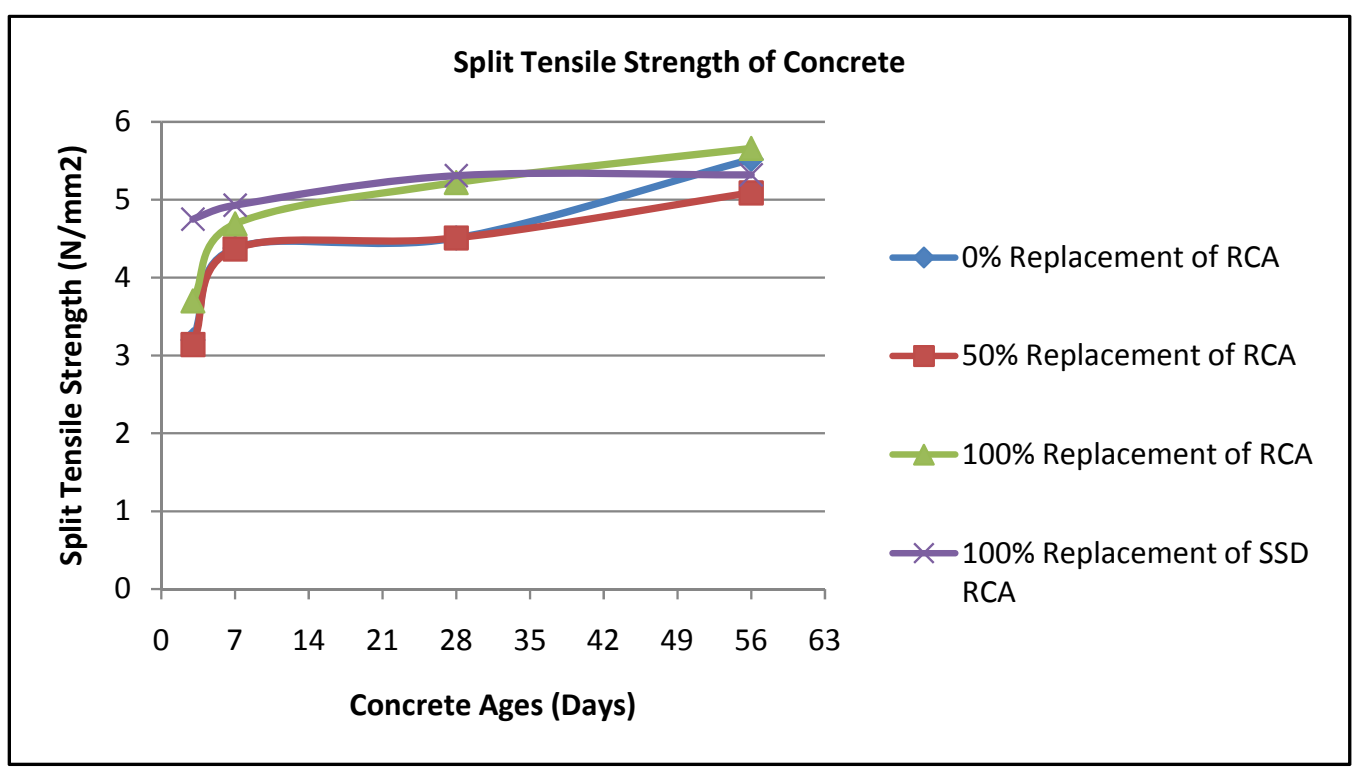

Figure 2 Split Tensile Strength of Hardened Concrete for Different Mix

The flexural test is carried out for each sample and the results are illustrated in Figure 3. From the results, the 3-day flexural strength of control concrete is lowest compared to 3-day flexural strength of RAC. The control concrete gains strength gradually and has higher flexural strength during later stage compared to the RAC. The 28-day flexural strength of control concrete is highest compared to 28-day flexural strength of RAC. The performance of RAC in terms of the flexural strength is not as good as the performance in terms of compressive strength and split tensile strength. This is because the recycled aggregates tend to deform more compared to than natural aggregates and the modulus of recycled aggregates is lower than the modulus of natural aggregates [15].

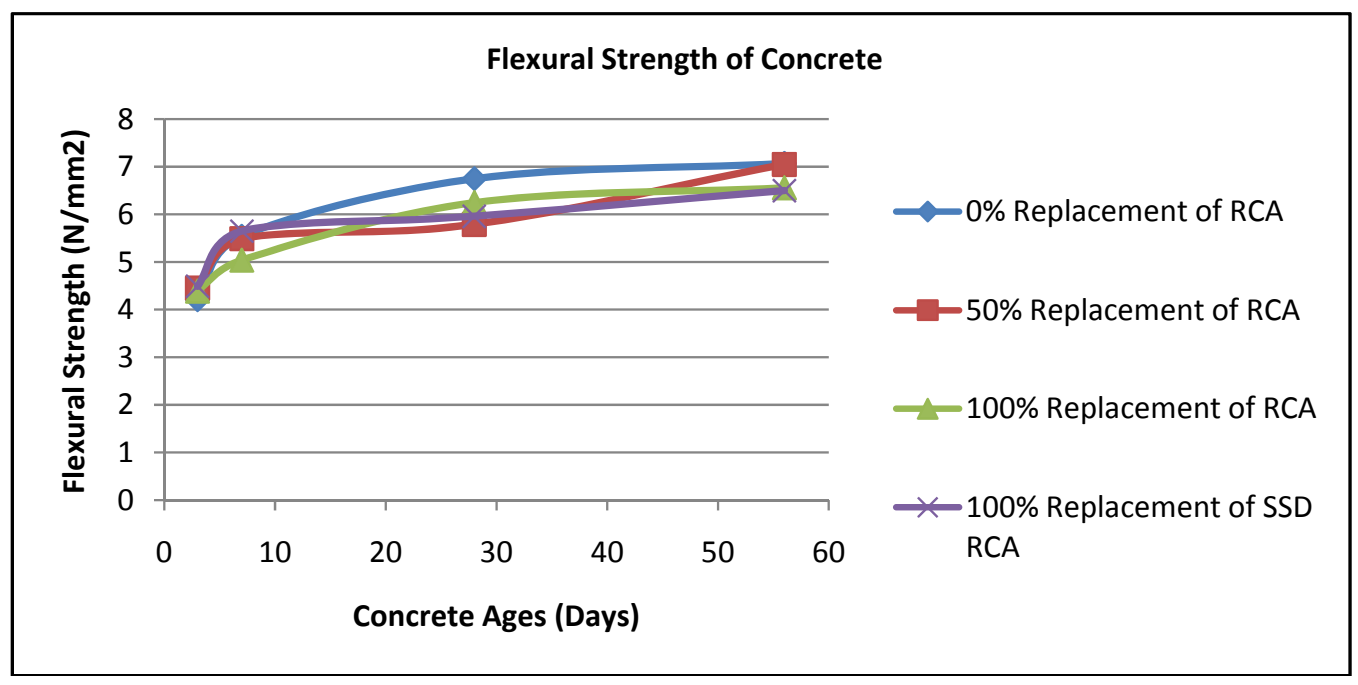

Figure 3 Flexural Strength of Hardened Concrete for Different Mix

\section{CONCLUSIONS}

Based on the experimental works from this research, the following conclusions are drawn:

i) The w/c used in all mixes is 0.41 . The proportion of cement: sand: gravel is 1: 1:11: 2.07.

ii) The workability of fresh concrete is not satisfied since the slump of recycled concrete made with $100 \%$ RCA is $0 \mathrm{~mm}$. It is recommended to saturate the RCA to saturated surface dry (SSD) condition before casting.

iii) RAC can achieve high compressive strength, split tensile strength as well as flexural strength.

iv) RAC has higher 28-day compressive strength and higher 28-day split tensile strength compared to control concrete. The 28-day flexural strengths of RAC are lower than that of natural concrete. 
v) Recycled aggregates obtained from site tested concrete cubes (RCA) shows good potential as coarse aggregate for the production of new concrete.

\section{ACKNOWLEDGEMENTS}

The authors are thankful to Mr. Eric Ngieng and Mr. Go from PPK (Pekerjaan Piasau Konkerit) for their help in the transportation of the materials. The authors also thank Paragon Concrete Company for supplying the materials that were used in this project.

\section{REFERENCES}

[1] Khalaf, F.M. et al. (2004). 'Recycling of demolished masonry rubble as coarse aggregate in Concrete: review.' ASCE J Mater Civil Eng (2004); 331340.

[2] Crentsil Sagoe, K.K., Brown T. and Taylor A. H. (1999). 'Performance of concrete made with commercially produced coarse recycled concrete aggregate.’ Journal of Cement and Concrete Research, 31 (2001); 707-712

[3] Rao, A., Jha, K.N. and Misra S. (2005). 'Use of aggregates from recycled construction and demolition waste in concrete.' Journal of Resources, Conservation and Recycling, 50 (2007); 71-81

[4] Oikonomou, N.D. (2004). 'Recycled Concrete Aggregates.’ Journal of Cement \& Concrete Composites 27 (2005); 315-318

[5] Portland Cement Association. (2008). Concrete Technology Home-Concrete Design and Production-Materials: Recycled Aggregates. Retrieved August 26, 2008, from http://www.cement.org/tech/cct_aggregates_recycled.asp

[6] Topcu, I.B. and Sengel, S. (2002). 'Properties of concrete produced with waste concrete aggregate.' Journal of Cement and Concrete Research, 34 (2004); 1307-1312

[7] González, F.B. and Martinez, A.F. (2006). 'Concrete with aggregates from demolition waste and silica fume. Materials and mechanical properties.' Journal of Building and Environment, 43 (2008); 429-437

[8] Malhotra, V.M. (1978). 'Use of recycled concrete as new aggregate'’ Proceedings of the Symposium on Energy and Resource Conservation in the Concrete Industry CANMET Rep. No. 76-8, CANMET, Ottawa, Canada (1978); 4-16.

[9] Rasheeduzzafar and Khan, A. (1984). 'Recycled concrete — a source of new concrete.' ASTM Cem., Concr., Aggregates, 6 (1) (1984); 17-27.

[10] Tavakoli M. and Soroushian P. (1996). 'Strengths of recycled aggregate concrete made using field-demolished concrete as aggregate.' Journal of ACI Materials. 93 (2) (1996 (March-April)); 182-190

[11] Poon, C.S. and Chan D. (2006). 'The use of recycled aggregate in concrete in Hong Kong.' Journal of Resource, Conservation and Recycling, 50 (2007); 293-305

[12] BS1881 Part 116. Method for Determination of Compressive Strength of Concrete Cubes. British Standard Institution.

[13] ASTM C496. Standard Test Method for Splitting Tensile Strength of Cylindrical Concrete Specimens. Annual Book of ASTM Standard.

[14] ASTM C78. Standard Test Method for Flexural Strength of Concrete (Using Simple Beam with Third-Point Loading). Annual Book of ASTM Standard.

[15] Frondistou, Y.S. (1977). ‘Waste Concrete as aggregate for New Concrete.’ ACI Journal, (August 1977); $373-376$. 